\title{
Redes neuro-fuzzy subsidiando o balanced scorecard em processo decisório holístico: o caso de uma instituição de educação profissional
}

\author{
Neuro-fuzzy networks subsidizing the balanced scorecard in process \\ holistic decision: \\ the case of the a institution of professional education
}

Dr. Marcelo Prado Sucena ${ }^{1}$

Eng. Tathyanne Bou Haya²

${ }^{1}$ Companhia Estadual de Engenharia de Transportes e Logística - CENTRAL

Rio de Janeiro - Brasil marcelosucena@gmail.com

${ }^{2}$ Mestranda de Engenharia de Produção da COPPE/UFRJ

Rio de Janeiro - Brasil tathyhaya@gmail.com

\section{Resumo}

Este trabalho teve como principal objetivo a criação de um modelo matemático usando Redes Neuro-Fuzzy, com a finalidade de gerar indicadores para avaliação holística das métricas do Balanced Scorecard em uma Instituição de Educação Profissional. O modelo permite gerar quatro indicadores parciais, que representam as perspectivas preconizadas no Balanced Scorecard (BSC), e um final, denominado Indicador da Corporação (IC), que agrupa todas as suas métricas. O modelo foi implementado eletronicamente, onde todos os dados processados foram extraídos do painel eletrônico da referida instituição. Pelos indicadores parciais e pelo IC geraram-se séries históricas que representam os meses de 2017. Os resultados demonstraram o ganho gerencial subsidiado pelos indicadores parciais da instituição, que refletem as perspectivas do BSC, que permitiram gerar outros cenários com visão holística temporal, denotando a relação de causas e efeitos.

Palavras-Chave: Indicadores. Gerenciamento Empresarial. Modelo Matemático.

\section{Abstract}

This work had as main objective the creation of a mathematical model using Neuro-Fuzzy Networks, in order to generate indicators for holistic evaluation of the Balanced Scorecard metrics in a Professional Education Institution. The model allows to generate four partial indicators, which represent the perspectives advocated in the Balanced Scorecard (BSC), and an end, denominated Indicator of the Corporation (IC), that groups all its metrics. The model was implemented electronically, where all data processed was extracted from the electronic panel of said institution. Partial indicators and $\mathrm{Cl}$ generated historical series that represent the months of 2017. The results showed the managerial gain subsidized by the institution's partial indicators, which reflect the perspectives of the BSC, which allowed generating other scenarios with a holistic temporal view, denoting the relation of causes and effects.

Keywords: Indicators. Business Management. Mathematical Model. 


\section{Considerações iniciais}

Devido à alta competitividade do mundo globalizado as instituições necessitam ser monitoradas para se identificar riscos, oportunidades e apontar melhorias. Com isso, estabelece-se o equilíbrio das demandas de ambiente interno e externo, fazendo mudanças estratégicas e elaboração de projetos, levando em consideração os pontos fracos e fortes, para que seja possível o alcance dos objetivos e metas.

Nos últimos anos, as instituições sem fins lucrativos têm crescido absurdamente, assumindo a categoria de instituições de grande porte, com alto orçamento estimado. Essas instituições sofrem impacto por não ter tradição de gestão consolidada e, por conta disso, tem aumentado a utilização de ferramentas para acompanhamento, gestão e avaliação de desempenho.

O Balanced Scorecard (BSC), que é um exemplo de ferramenta de gestão estratégica, combina os indicadores financeiros e não financeiros da organização, além de ser considerado um instrumento de medida que faz inclusão de todos os fatores críticos de sucesso, trabalhando com a missão e a estratégia da organização em um conjunto de medidas de desempenho. Essas medidas possibilitam a existência da correlação entre as gestões operacional e estratégica, permitindo a realização de um feedback para identificação das estratégias com mais eficiência.

Mas, o que se percebe, é que o BSC em si não propõe avaliar o valor da organização de forma holística, isto é, por indicadores que agreguem todas as suas medidas de desempenho, permitindo-se visualizar a organização como um todo. São exemplos de trabalhos com BSC aplicados em vários setores empresariais, focando-se na avaliação de desempenho, mas dissociada do foco holístico: Batocchio, Minatogawa e Anholon (2016), Medel-González et al. (2016), Mario e Verdu (2015), Lutif Junior (2012), Gadelha e Mâsih (2007), Ghelman (2006), Rodrigues, Pantaleão e Schuch (2003), Mâsih, Marinho e Selig (2002).

Como o cenário desse estudo está associado à instituição de educação foram identificados estudos sobre BSC neste ramo, destacando-se Petri et al. (2019), Costa et al. (2018), Knoll (2018), Pereira (2014), Lima (2009) e Souza (2005).

Percebe-se diante da revisão tratada anteriormente que a necessidade de representar a corporação de forma holística é enxergada pelos seus pilares, mas não pela geração de uma única medida que represente tais pilares.

Nesse contexto, o objetivo principal deste trabalho é a elaboração de um modelo matemático que agregue todas as medidas de desempenho, tratadas originalmente de forma isolada no BSC de uma instituição de educação profissional, permitindo-se gerar indicadores que representem os pilares individualmente, além de outro indicador que retrate a condição da corporação de forma sistêmica. 


\section{Metodologia proposta}

Segundo Silva e Menezes (2005) este trabalho pode ser classificado de acordo com os seguintes aspectos:

- Natureza: é considerado como pesquisa aplicada, pois tem como objetivo obter conhecimento para desenvolver proposta de melhoria para aprimorar a ferramenta de gestão usada na instituição;

- Objetivos: viés exploratório, visando tornar os resultados do BSC mais compreensíveis, para que sirva de referência para futuros estudos;

- Abordagem: qualitativa, pela necessidade de compreender os acontecimentos em vários níveis do processo;

- Método: o trabalho é apresentado como um estudo de caso que, de acordo com a complementação de Gil (2008), é caracterizado pelo estudo profundo e exaustivo de um ou de poucos objetos, de maneira a permitir o seu conhecimento amplo e detalhado, tarefa praticamente impossível mediante os outros tipos de delineamentos considerados.

Sendo assim, para se atingir o objetivo determinado será necessário seguir os seguintes passos:

- Definir as métricas usadas no BSC da instituição, por investigação de documentos e registros em painel eletrônico próprio;

- Desenvolver modelo matemático seguindo os subitens:

- Transformar as métricas em variáveis de entrada Fuzzy;

- Agrupar as medidas por perspectivas do BSC por meio de estrutura topológica de Rede NeuroFuzzy;

- Adequar as variáveis de saída da Rede Neuro-Fuzzy para se gerarem os indicadores parciais que reflitam as perspectivas do BSC;

o Pelo agrupamento dos indicadores parciais elaborar o indicador holístico denominado IC.

- Implementar o modelo matemático em aplicativo computacional para processamento dos dados do estudo de caso, gerando-se séries históricas que permitirão a análise estratégica holística pelo viés corporativo. 


\section{Sustentação teórica}

\subsection{Gestão estratégica}

Segundo Coutinho (2005), a Gestão Estratégica visa o alcance dos objetivos estabelecidos no Planejamento Estratégico para que o sucesso da instituição seja realizado, promovendo a melhoria contínua de toda instituição, pela execução, monitoramento, avaliação, ajustes e gerenciamento, de forma que se reduzam os desperdícios, evitando riscos futuros e realizando a manutenção nas informações e ações, de maneira que elabore projetos de mudanças estratégicas com foco em todas as áreas da instituição.

A gestão estratégica é essencial tanto quanto a implementação e formulação do Planejamento Estratégico, pois acrescenta novos elementos de ação sistemática, a fim de avaliar a situação e aplicar com eficácia os recursos disponíveis na instituição, sendo considerado um orientador dentro do fluxo de decisões.

De acordo com Oliveira (2007), o Planejamento Estratégico é composto pelos seguintes elementos:

- Missão: é a essência da instituição, pois consiste na definição dos seus fins estratégicos gerais. Tratase das definições dos objetivos da instituição e serve de guia para os funcionários;

- Visão: é o estado futuro da instituição, o que ela deseja se tornar, de modo que conduza a instituição para o futuro;

- Valores: conjunto de princípios que são essenciais para a estruturação da instituição, de forma que contribua para a coerência do trabalho e busca realizar a visão da instituição;

- Objetivos estratégicos: são definidos de forma clara para que se alcancem os resultados que a instituição deseja e possibilite o cumprimento da missão e alcance da visão;

- Indicadores e metas: instrumento de medição do desempenho da instituição de forma que oriente e analise a real situação pelo alcance das metas estabelecidas, proporcionando maior previsibilidade nas atividades estratégicas.

Ainda segundo Coutinho (2005), para o desenvolvimento da gestão estratégica existe diversos passos a serem seguidos para uma avaliação e monitoramento mais assertivo:

- Formulação da Estratégia: uma atividade que envolve identificar as ameaças e oportunidades do ambiente interno e externo da instituição;

- Diagnóstico: realiza um mapeamento de todas as informações atualizadas da instituição para analisar os resultados de acordo com as estratégias vigentes;

- Direcionamento: implementar ações com foco na necessidade da instituição;

- Gerenciamento: monitorar, avaliar e analisar todo risco e oportunidade existentes. 
Portanto, a gestão estratégica auxilia a instituição na apuração de cada processo e no desenvolvimento de ações corretivas constantes, visando manter as vantagens competitivas, o crescimento e a sobrevivência, consistindo em atingir os objetivos e agir antecipadamente com a perspectiva de que é possível interferir na construção das estratégias.

\subsection{Balanced scorecard}

No início da década de 1990, o BSC foi desenvolvido por David Norton e Robert Kaplan, devido ao fato da gestão das instituições na época se limitarem apenas às informações financeiras (Kaplan e Norton,1997). Eles perceberam que havia necessidade de se desenvolver uma ferramenta capaz de criar novas técnicas e estratégias para alinhar as instituições, de forma que unisse os indicadores não financeiros e financeiros, impulsionando o desempenho estratégico externo e interno da instituição.

O BSC, portanto, é uma ferramenta para gerenciar o desempenho da instituição que tem como foco implementar e alinhar estratégias, transformá-las em ações eficientes, tendo a oportunidade de compartilhar seus objetivos e medidas tangíveis e mensuráveis de curto e longo prazos, de modo que não seja para controlar, mas para comunicar e desenvolver aprendizados integrando com o planejamento estratégico.

Segundo Kaplan e Norton (1997), a ferramenta precisa ser manipulada pela alta administração da instituição, pois precisa ser utilizada como forma de decisões e implementação de ações e possíveis mudanças na própria estratégia para garantir o alcance das metas estabelecidas de modo que obtenha os resultados esperados. Eles consideraram quatro perspectivas: financeira, clientes e sociedades, processos internos e aprendizado e crescimento, a saber:

- Perspectiva Financeira: identifica todos os objetivos e medidas financeiras, avalia a lucratividade da instituição e analisa seu crescimento e desenvolvimento;

- Perspectiva Cliente e Sociedade: permite que a instituição tenha conhecimento da sua reputação no segmento de mercado para que seja viável o destaque nas categorias de tempo, qualidade, escopo e custo, pois visará o sucesso da empresa nesse segmento;

- Perspectiva Processos Internos: focada nas diretrizes dos objetivos, que permitam processos de inovação e operacionais relacionados à satisfação e fidelidade dos clientes, tendo como foco criação de produtos e serviços de alta qualidade;

- Perspectiva Aprendizado e Crescimento: objetiva propiciar a análise para se investir em qualificação e melhorias dos colaboradores da instituição, de modo que se torne fundamental para que o crescimento interno seja eficaz e necessário para o alcance das metas propostas. 
Ainda de acordo Kaplan e Norton (1997), o BSC deixou de ser um sistema de mensuração de desempenho para se tornar uma grande ferramenta de gestão estratégica. Ela incentiva o desenvolvimento das áreas da instituição pelas estratégias traçadas ao longo do manuseio do BSC.

\subsection{Redes neuro-fuzzy}

Rezende (2005) expõe que uma Rede Neuro-Fuzzy (RNF) combina a topologia das Redes Neurais Artificiais (RNA) com a Inferência Fuzzy no processamento neuronal. Dessa forma, é possível desenvolver um modelo que permita se incorporar dados quantitativos e qualitativos, lineares e não lineares, tornando adaptável às necessidades das soluções dos problemas do mundo real.

\subsubsection{RNA}

As Redes Neurais Artificiais (RNA) são sistemas paralelos distribuídos, inspirados no funcionamento do cérebro humano, que podem aprender a predizer e se adaptar ao mundo real. São compostas por unidades de processamento simples, denominadas "neurônios", que processam determinadas relações (Sucena, 2007).

Os neurônios são interligados por canais de comunicação que são associados a um determinado peso, processando sinais nos canais de entrada e os enviando para uma saída que é ligada aos outros neurônios (Shaw \& Simões, 1999).

As RNA são sistemas inteligentes e dinâmicos, que têm como capacidade tomar decisões complexas, baseando-se em dados fornecidos pelo ser humano (Vellasco, 2007).

A busca crescente nas RNA deve-se principalmente ao fato da sua capacidade de adaptação, bom desempenho com solução de problemas, ausência da necessidade de suposição de uma hipótese e também dispensa regressões estatísticas para encontrar parâmetros, ficando tudo a cargo das ligações dos neurônios das RNA.

Em 1943, MC Culloch e Pitts propuseram um modelo de neurônio artificial chamado MCP (Figura 2), sendo composto de $n$ entradas e uma única saída (Medeiros, Souza, \& Maitelli, 2003), tornando possível o conhecimento distribuído por toda rede e a determinação da intensidade de conexões entre os neurônios. 
Figura 1 - Modelo de Neurônio Artificial MCP

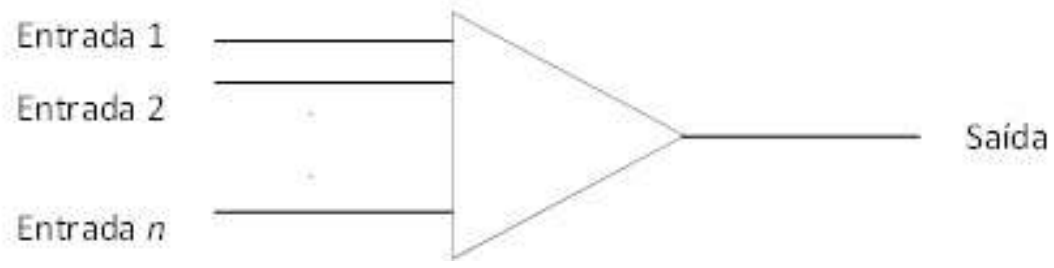

Fonte: Medeiros, Souza e Maitelli (2003).

\subsubsection{Lógica fuzzy}

A Lógica Clássica Aristotélica permite tratar hipóteses contendo apenas "1" para verdadeiro e "O' para falso, tornando as análises rígidas e com definições exatas. A Lógica Fuzzy diferencia-se por se tratar dos infinitos valores entre " 0 " e " 1 ", fazendo com que um elemento possa parcialmente pertencer a um subconjunto classificado como termos linguísticos (Adamowicz, Barboza \& Sampaio, 2002).

A Teoria Fuzzy se difundiu após a publicação do artigo Fuzzy Sets, Information and Control, pelo professor Zadeh, em 1965, na revista Information and Control - Volume 8, nas páginas 338 a 353, em 1965 (Tanaka, 1997) e atualmente objetiva, principalmente na área de processos decisórios, a modelagem de dados incertos, imprecisos e ambíguos, conduzindo a maior adequação à realidade, associando-se a modelagem computacional ao raciocínio humano.

Segundo Shaw e Simões (1999) para a apresentação de um conjunto Fuzzy faz-se necessário o conhecimento dos cinco símbolos conceituais, conforme exemplificados na Figura 2, que são:

- Conjunto de Elementos, como por exemplo, "Índice" em "Indicadores";

- Variável Linguística: tem como valor sentenças ou características e não números, como exemplifica "Índice de Indicadores";

- Termo Linguístico: são nomes e/ou adjetivos que representam a variável linguística, por exemplo, "Risco", "Atenção" e "Segurança";

- Universo de Discurso: intervalo estimado que se usa como referência para um atributo, exemplificado no registro da abscissa como "Índice" que varia entre 0 e 1 ;

- Grau de Pertinência: cada elemento do conjunto Fuzzy assume um valor dentro do intervalo $[0,1]$ (ordenada), sendo possível determinar o quanto aquele elemento pertence ao conjunto, permitindo uma transição gradual.

Para Ross (2010) um conjunto Fuzzy A, com um universo de discurso $X$ com $i$ elementos, pode ser representado: 
Na forma discreta, quando o universo é finito, por:

$$
A=\mu_{A}\left(x_{1}\right) / x_{1}+\mu_{A}\left(x_{2}\right) / x_{2}+\ldots+\sum_{i=1}^{n} \mu_{A}\left(x_{i}\right) / x_{i}
$$

em que $\mu_{A}\left(x_{i}\right)$ é o grau de pertinência do elemento $i$ e $x_{i}$ valor do elemento $i$ no universo de discurso $X$

Na forma contínua, quando o universo é infinito, por

$$
A=\int_{x} \mu_{A}\left(x_{i}\right) / x_{i}
$$

Figura 2 - Exemplo da Variável Índice de Indicadores

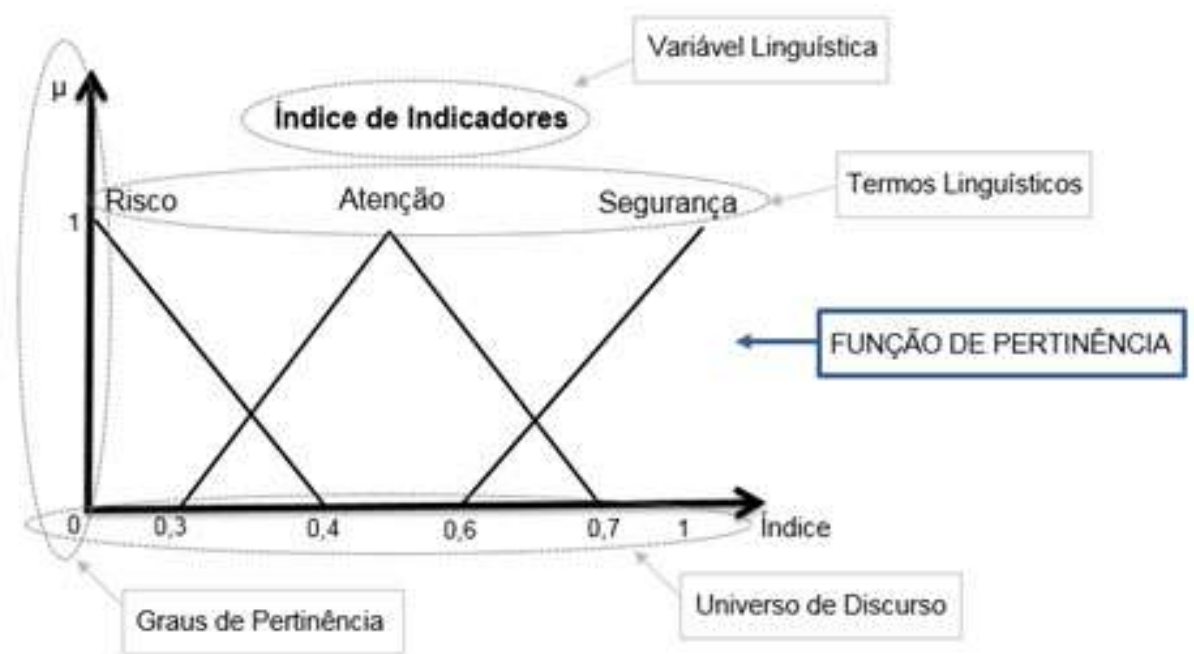

Fonte: Autores.

Segundo Amendola, Souza e Barros (2007), as funções de pertinência mais comuns para implementação computacional são as triangulares e as trapezoidais.

A função de pertinência triangular é caracterizada por três valores do universo de discurso $(a, b, c)$, sendo que $a$ e $c$ determinam o intervalo dentro da função, que assumem graus de pertinência iguais a zero; e $b$ é valor com o maior grau de pertinência. Assim, um número Fuzzy é considerado triangular se sua função de pertinência for da seguinte forma:

$$
\mu_{\mathrm{A}}(x)=\left\{\begin{array}{c}
0 \text { for } x<a, \\
\frac{x-\mathrm{a}}{\mathrm{b}-\mathrm{a}} \text { for } a \leq x \leq b, \\
\frac{\mathrm{c}-\mathrm{x}}{\mathrm{c}-\mathrm{b}} \text { for } b \leq x \leq c, \\
0 \text { for } x>c,
\end{array}\right.
$$

A função de pertinência trapezoidal é composta pelos valores (a,b,c e d), em que $a$ e $d$ assumem graus de pertinência iguais a zero; e $b$ e $c$ são extremos de $x$ constante com grau máximo de pertinência. Desta forma um número Fuzzy trapezoidal é expresso da seguinte forma: 


$$
\operatorname{trap}(x: a, b, c, d)=\left\{\begin{array}{cc}
0 & x<a \\
\frac{x-a}{b-a} & a \leq x<b \\
1 & b \leq x<c \\
\frac{d-x}{d-c} & c \leq x<d \\
0 & x \geq d
\end{array}\right.
$$

A estrutura de um sistema de Inferência Fuzzy, segundo Wang (1996), consiste nas seguintes etapas:

- Fuzzyficação: os valores de entrada do mundo real, que são coletados em análises do processo, são Fuzzyficados, obtendo-se um grau de pertinência em cada subconjunto Fuzzy;

- Inferência: permite associar as combinações feitas em cada variável de entrada passando por um processo de avaliação, por meio de regras definidas previamente;

- Defuzzyficação: é o momento que se passa do estado da variável de saída para um valor numérico real, podendo ser desenvolvida por diversos métodos, sendo um dos mais ressaltados centro dos máximos, dada pela média ponderada das métricas pelos graus de pertinência associados.

\section{Desenvolvimento do modelo matemático}

Conforme exposto na metodologia, na seção 2, para desenvolvimento do modelo matemático faz-se necessário seguir os subitens adiante.

\subsection{Definições das medidas}

A instituição do estudo de caso contém dez medidas distribuídas entre as perspectivas do BSC. Cada uma delas será transformada em uma variável de entrada Fuzzy. A seguir as métricas que serão ressaltadas junto de suas perspectivas do BSC.

Perspectiva Financeira (IP1)

- Resultado Financeiro (RF=VEF1): capacidade de gerar o equilíbrio financeiro, sendo a relação entre a receita total executada e a despesa total executada na instituição. Essa medida segue o intervalo $[0,3]$.

- Receita de Serviços (RS=VEF2): evolução da receita de serviço atual em relação a anterior, entre períodos, tendo como critério a variação. RS utiliza o intervalo [0,3]. 
- Execução Financeira do Programa Gratuidade (PG=VEF3): garante a aplicação de recursos no PG, medindo a execução financeira do recurso efetivamente aplicado e o compromisso com o programa. Como o anterior, tem intervalo $[0,3]$.

$\checkmark$ Perspectiva Cliente e Sociedade (IP2)

- Atendimento Corporativo ( $\mathrm{AC}=\mathrm{VEF} 4$ ): representa a quantidade de empresas contratantes para serviços educacionais, independentemente de serem clientes da instituição, sendo possível a verificação da evolução do atendimento corporativo, entre períodos, em relação à quantidade de empresas atendidas. Segue o intervalo $[0,3]$.

- Matrícula Total (MT=VEF5): execução da matrícula da produção educacional, computando matrícula total, tanto de cursos presenciais quanto à distância, tendo como referência o intervalo $[0,3]$.

- Carga Horária Apurada (CHA=VEF6): execução da carga horária da produção educacional, sendo computada tanto dos cursos presenciais quanto de EAD. É utilizado o intervalo [0,3].

$\checkmark$ Perspectiva Processos Internos (IP3)

- Matrícula em cursos do Modelo Pedagógico (MP=VEF7): consolida a quantidade de matrículas executadas no MP, no intervalo $[0,3]$.

- Implantação do Plano Diretor de Tecnologia da Informação (PDTI=VEF8): desenvolve infraestrutura e recursos de Tecnologia da Informação, integrado e voltado ao negócio, fazendo a medição da quantidade de projetos desenvolvidos pelo PDTI. É utilizado o intervalo [0,3].

- Oferta de Planos de Cursos Nacionais (VEF9): quantidade de planos de cursos no MP, ofertados ao mercado. Utiliza o intervalo $[0,3]$.

Perspectiva Aprendizado e Crescimento (IP4)

- Investimento em qualificação dos colaboradores (VEF10): valorização e qualificação das pessoas, avaliando o investimento que a instituição efetuou para aprimoramento de competências de seus empregados, incluindo capacitações e treinamentos do pessoal, além de eventos. Também utiliza o intervalo $[0,3]$.

\subsection{Variáveis de entrada fuzzy}

As métricas citadas anteriormente serão transformadas em variáveis de entrada Fuzzy que são definidas pelos seus universos de discurso, termos linguísticos e funções de pertinências.

A Figura 3 denota a representação das variáveis de entrada Fuzzy com universo de discurso que varia entre 0 e 3, que são: Resultado Financeiro, Receitas de Serviço, Execução Financeira do PG e Atendimento Corporativo. Todas serão apresentadas com os termos linguísticos: Risco, Atenção e Segurança. Os referidos Termos Linguísticos, bem como os Universos de Discurso, seguem as mesmas nomenclaturas e valores utilizados na corporação de ensino em sua base de gestão. 
Figura 3 - Modelagem das Variáveis RF, RS, PG e AC

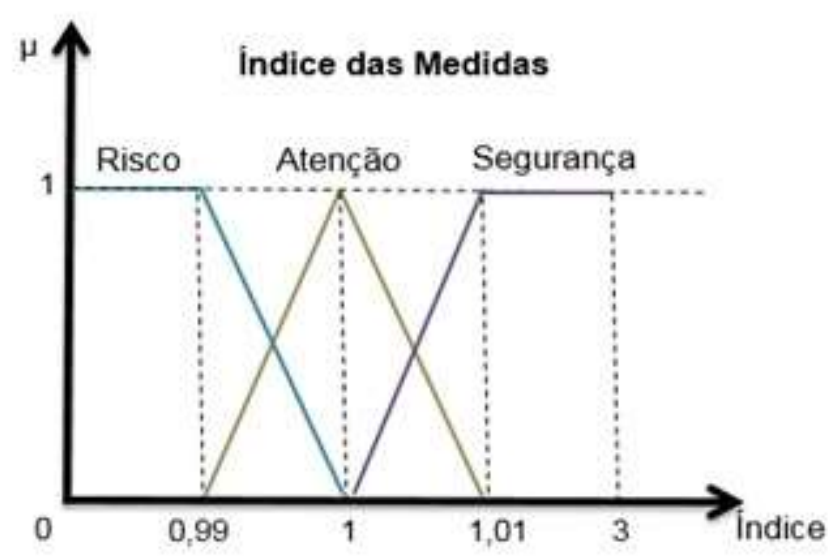

Fonte: Autores.

A Figura 4, representa as variáveis de entrada Fuzzy Matrícula Total, Carga Horária Apurada, Matrícula em Cursos de MP, Ofertas de Planos de Cursos Nacionais e Investimento em qualificação dos colaboradores, que têm os mesmos termos linguísticos (Risco, Atenção e Segurança), com universo de discurso variando entre 0 e 3.

Figura 4 - Modelagem das Variáveis MT, CHA, MP, PDTI, Oferta de Planos de Cursos e Investimento em qualificação dos colaboradores

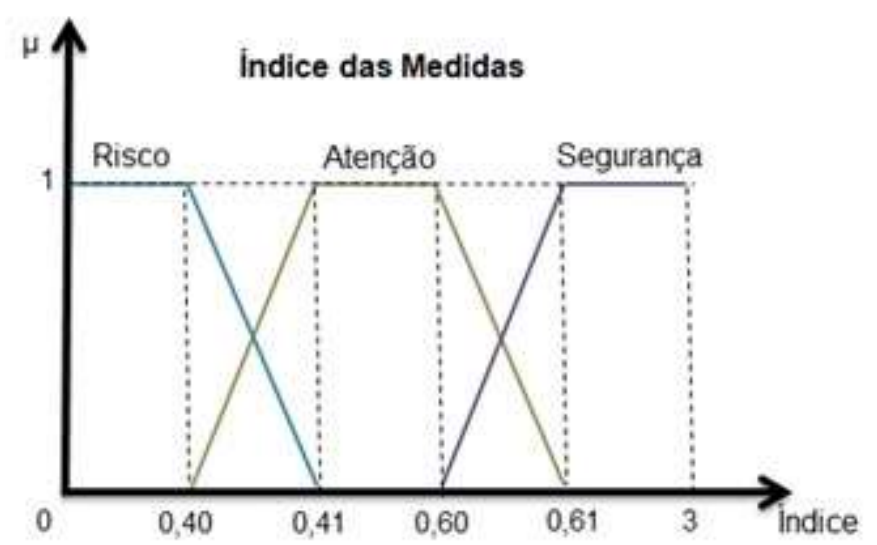

Fonte: Autores.

\subsection{Elaboração da rede neural artificial}

Esse trabalho utiliza os conceitos da topologia das RNA composta por quatro neurônios (N1 à N4), que agregam dez variáveis de entrada Fuzzy (VEF1 à VEF10) e resultam em quatro variáveis de saída Fuzzy (VEF11 à VEF13 e IC). 
Conforme proposição do objetivo desse trabalho, as variáveis de saída VEF11 à VEF13 representam os pilares ou as perspectivas do BSC, os indicadores parciais (IP1, IP2 e IP3), e IC representa a visão holística da corporação (IC). A figura 5 apresenta a diagramação topológica da RNA.

Figura 5 - Diagramação da RNA

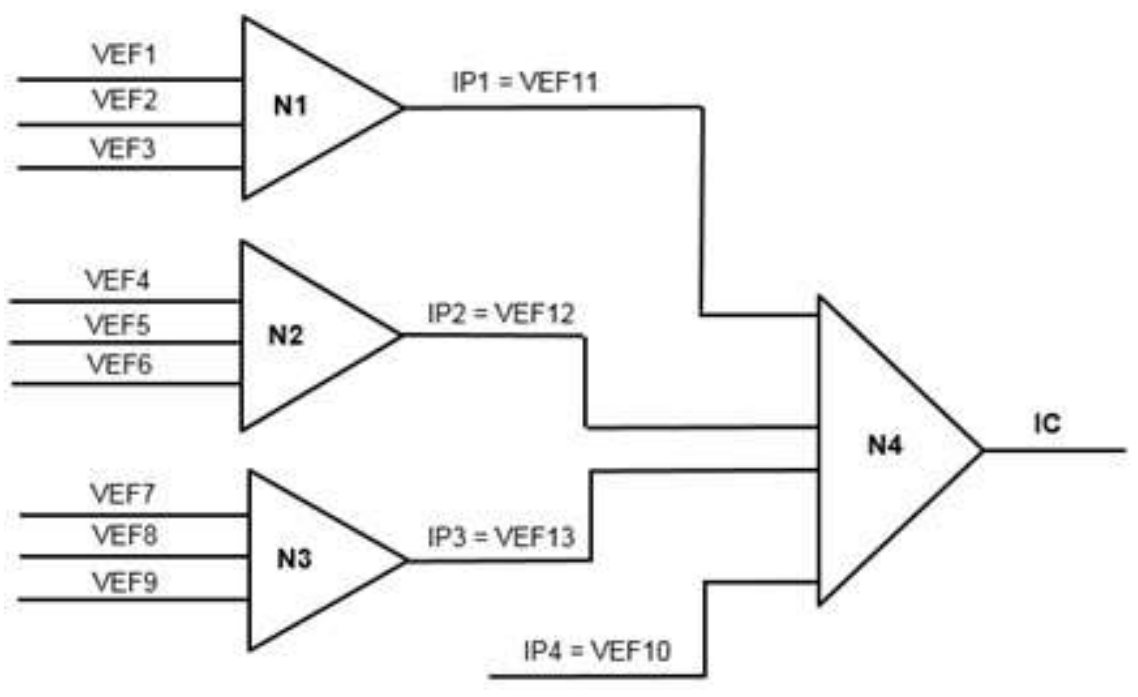

Fonte: Autores.

\subsection{Variáveis de saída fuzzy}

As três variáveis de saída Fuzzy (VEF11 à VEF13), além da variável de entrada VEF10, são utilizadas como variáveis de entrada Fuzzy a serem processadas no N4, gerando IC. A modelagem dessas variáveis de entrada Fuzzy é demonstrada nas figuras 6 a 9 a seguir.

- Indicador da Perspectiva Financeira (IP1 = VEF11)

Figura 6 - Função de Pertinência do Indicador da Perspectiva Financeira

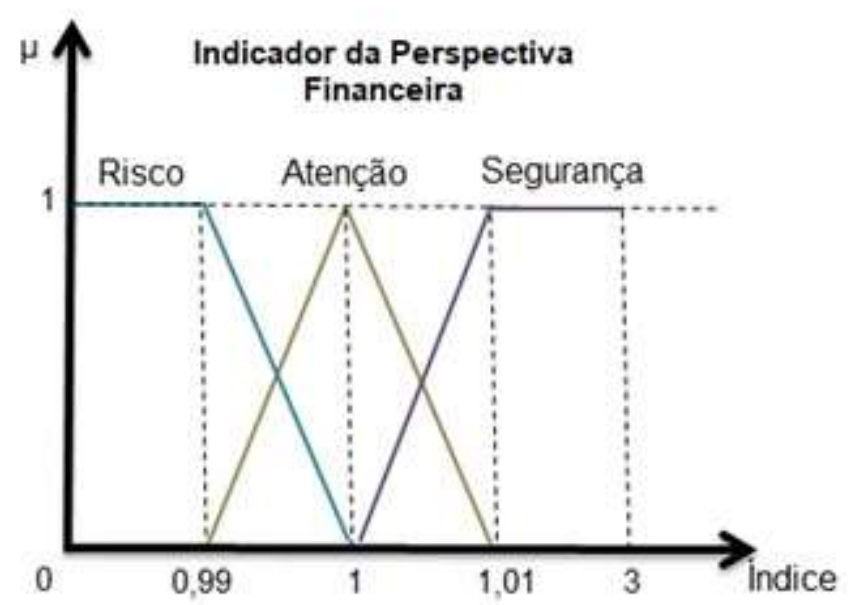

Fonte: Autores. 
- Indicador da Perspectiva Cliente e Sociedade (IP2 = VEF12)

Figura 7 - Função de Pertinência do Indicador da Perspectiva Cliente e Sociedade

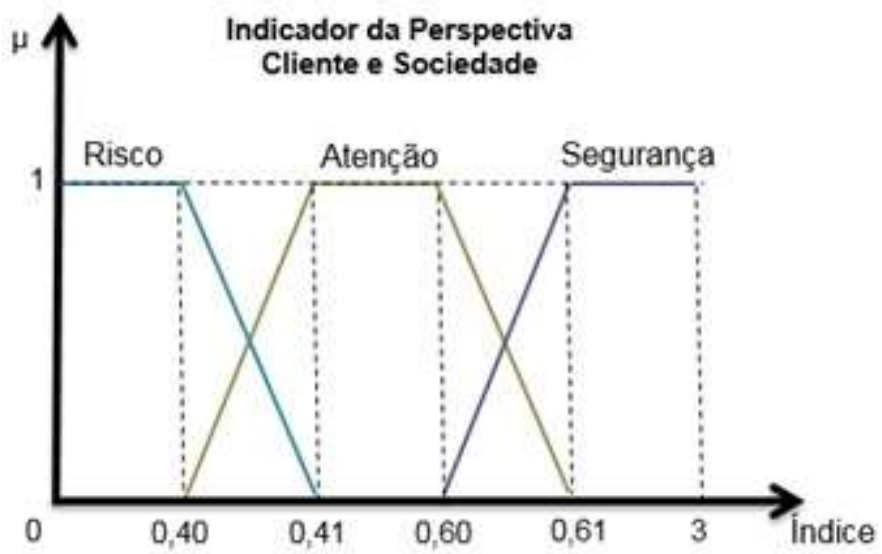

Fonte: Autores.

- Indicador da Perspectiva Processos Internos (IP3 = VEF13)

Figura 8 - Função de Pertinência do Indicador da Perspectiva Processos Internos

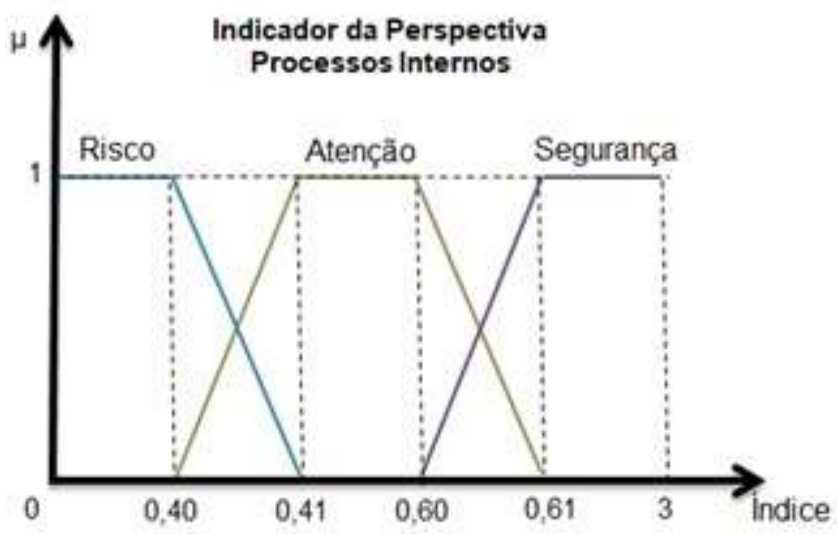

Fonte: Autores.

- Indicador da Perspectiva Aprendizado e Crescimento (VEF10) 
Figura 9 - Função de Pertinência do Indicador da Perspectiva Aprendizado e Crescimento

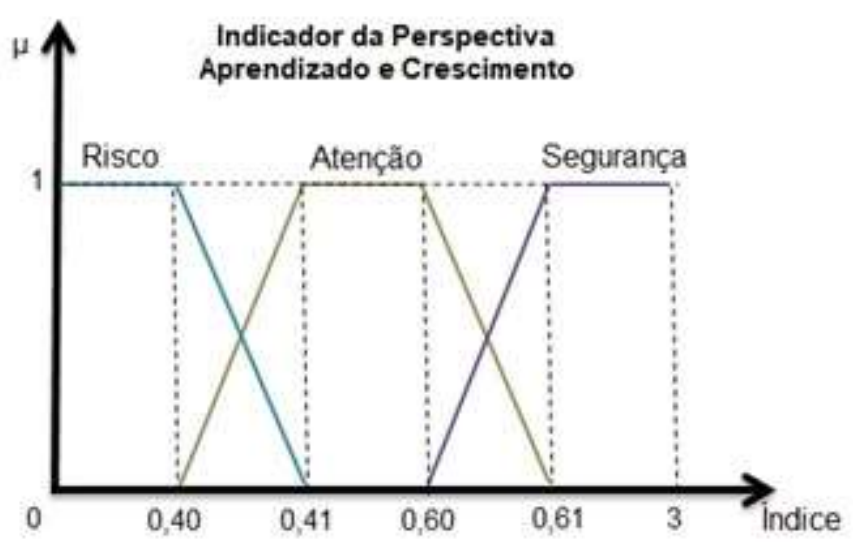

Fonte: Autores.

Para que essas variáveis de saída Fuzzy resultem em um valor numérico Real é necessário utilizar o método de Defuzzyficação do Centro dos Máximos.

\section{Estudo de caso}

\subsection{Objeto do estudo de caso}

A instituição do estudo de caso é considerada de referência nacional de educação profissional voltada para o setor do comércio de bens, serviços e turismo, atuando desde a década de 1940 do século XX.

Em 2016, a instituição implementou o BSC, ferramenta que visa descrever a estratégia de forma clara por meio de um mapa estratégico para monitorar as ações e objetivos da instituição, no qual aponta o foco institucional para realização dos planos de ações da instituição.

Para este mesmo fim, anteriormente eram utilizadas outras ferramentas, necessitando-se mobilização dos gestores e colaboradores de todo a empresa para debate que embasou a melhor formulação estratégica, haja vista que 2017 foi marcado por um quadro socioeconômico e político nacional de intensificação da crise, com expectativa de mudança no cenário recessivo apenas para o segundo semestre.

A percepção antecipada dos sinais da crise permitiu a instituição estabelecer contramedidas de prevenção, gerando diferentes ações (projetos e atividades), que convergem na otimização de processos, racionalização dos recursos e maior eficiência operacional e gerencial.

Com as quatro perspectivas do BSC (Financeira, Clientes e Sociedade; Processos Internos, e Aprendizado e Crescimento), o Planejamento Estratégico definiu os projetos e ações a serem realizados, para garantir maior convergência com os objetivos estabelecidos pela instituição, definindo indicadores e metas para serem padronizados. 


\subsection{Dados de entrada e resultados}

Os dados das métricas dos meses de 2017 que compuseram as variáveis de entrada do modelo matemático foram obtidos junto ao painel eletrônico da instituição. Este Painel Eletrônico é a interface de um software que foi desenvolvido pela instituição para ser a base de pesquisa do BSC e, como tal, tem acesso restrito aos seus colaboradores. Os registros de tais dados que serviram para compor as variáveis de entrada do modelo matemático estão apresentados nas Tabelas 1 a 4, para os neurônios N1 a N4, respectivamente.

Ao se observar a diagramação topológica da RNA apresentada na Figura 5 percebe-se que à esquerda estão dispostas as variáveis de entrada que alimentam os neurônios N1 a N4 e, por consequência, após o seu processamento conforme apresentado por Wang (1996), são geradas as variáveis de saída IP1 a IP3 e IC, respectivamente. Os valores dessas saídas também estão representados nas Tabelas 1 a 4 .

As séries históricas formadas com os valores de saída (após processamento da RNA) para os meses referentes a 2017 estão expostas nas Figuras 10 a 14. Os referidos valores representam as perspectivas do BSC, além do Indicador da Corporação, que reflete todas as métricas usadas como variáveis de entrada do modelo matemático.

Tabela 1 - Entradas e Saída IP1, de N1

\begin{tabular}{|l|r|r|r|r|}
\hline \multirow{2}{*}{ MÊS } & \multicolumn{4}{|c|}{ N1 } \\
\cline { 2 - 4 } & VEF1 & VEF2 & \multicolumn{1}{|c|}{ VEF3 } & \multicolumn{1}{|c|}{ IP1 } \\
\hline \multirow{2}{*}{ JAN } & 1,11 & 0,76 & 0,68 & 0,85 \\
\hline FEV & 1,03 & 0,78 & 0,72 & 0,84 \\
\hline MAR & 1,03 & 0,96 & 0,93 & 0,98 \\
\hline ABR & 1,09 & 0,93 & 0,84 & 0,96 \\
\hline MAI & 1,06 & 1,03 & 0,89 & 1 \\
\hline JUN & 1 & 0,94 & 0,95 & 0,96 \\
\hline JUL & 0,97 & 0,99 & 0,66 & 0,87 \\
\hline AGO & 0,98 & 1,09 & 1,14 & 1,07 \\
\hline SET & 1,02 & 0,98 & 1,09 & 1,03 \\
\hline OUT & 0,98 & 1,01 & 1,3 & 1,1 \\
\hline NOV & 1,01 & 1,17 & 1,11 & 1,11 \\
\hline DEZ & 1,45 & 0,98 & 0,61 & 1,01 \\
\hline
\end{tabular}

Fonte: Autores. 
Figura 10 - Evolução em 2017 do IP1 - Perspectiva Financeira do BSC

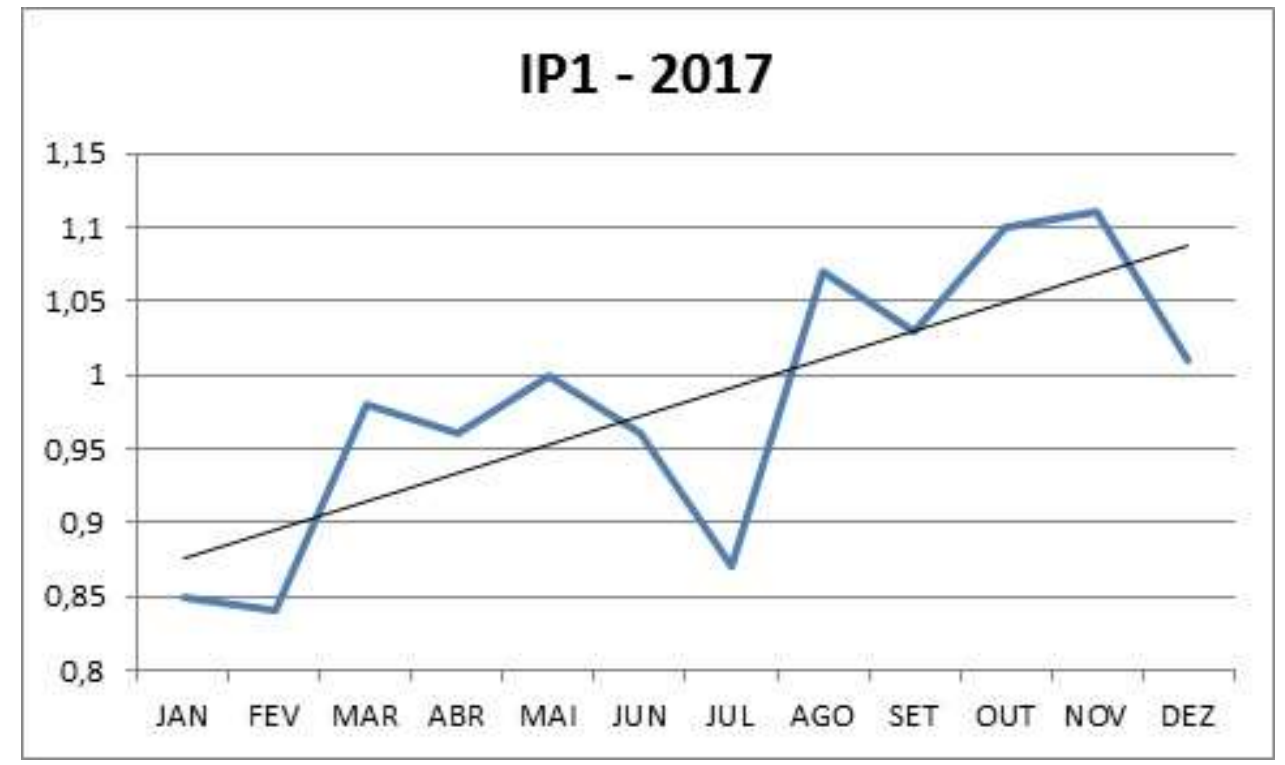

Fonte: Autores.

Tabela 2 - Entradas e Saída IP2, de N2

\begin{tabular}{|l|r|r|r|r|}
\hline \multirow{4}{*}{ MÊS } & \multicolumn{3}{|c|}{ N2 } \\
\cline { 2 - 4 } & VEF4 & \multicolumn{1}{|c|}{ VEF5 } & \multicolumn{1}{|c|}{ VEF6 } & \multicolumn{1}{|c|}{ IP2 } \\
\hline \multirow{2}{*}{ JAN } & 1,03 & 1,79 & 0,72 & 1,18 \\
\hline FEV & 1,25 & 0,81 & 0,81 & 0,95 \\
\hline MAR & 1,44 & 0,93 & 1 & 1,12 \\
\hline ABR & 1,54 & 0,74 & 0,92 & 1,07 \\
\hline MAI & 1,86 & 0,65 & 0,93 & 1,14 \\
\hline JUN & 1,53 & 0,67 & 0,92 & 1,04 \\
\hline JUL & 1,75 & 0,88 & 0,81 & 1,15 \\
\hline AGO & 1,84 & 1,1 & 1,04 & 1,33 \\
\hline SET & 1,59 & 0,84 & 1,01 & 1,15 \\
\hline OUT & 1,84 & 0,95 & 1,15 & 1,31 \\
\hline NOV & 1,94 & 0,74 & 1,64 & 1,44 \\
\hline DEZ & 1,85 & 0,21 & 0,29 & 0,78 \\
\hline
\end{tabular}

Fonte: Autores. 
Figura 11 - Evolução em 2017 do IP2 - Perspectiva Cliente e Sociedade do BSC

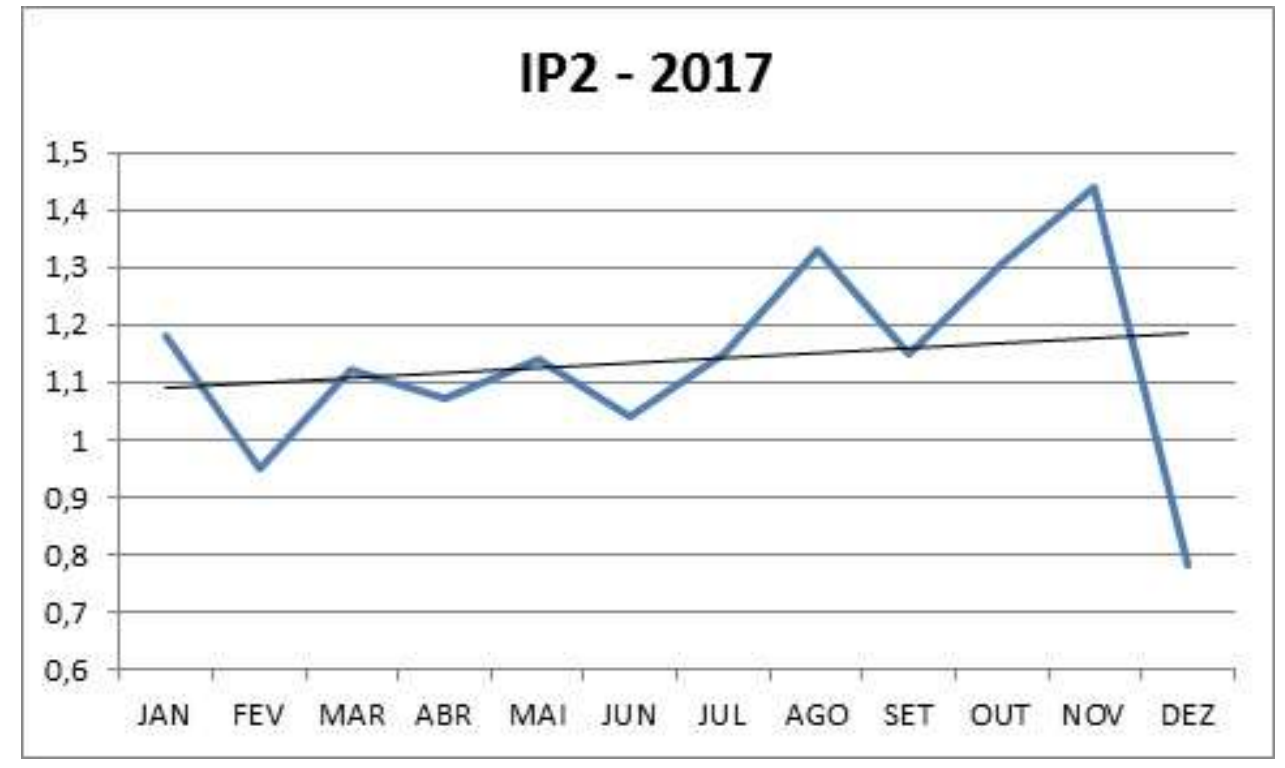

Fonte: Autores.

Tabela 3 - Entradas e Saída IP3, de N3

\begin{tabular}{|l|r|r|r|r|}
\hline \multirow{2}{*}{ MÊS } & \multicolumn{4}{|c|}{ N3 } \\
\cline { 2 - 4 } & VEF7 & \multicolumn{1}{|c|}{ VEF8 } & \multicolumn{1}{|c|}{ VEF9 } & \multicolumn{1}{|c|}{ IP3 } \\
\hline \multirow{2}{*}{ JAN } & 1,53 & 0,59 & 1 & 0,95 \\
\hline FEV & 1,03 & 0,73 & 1,45 & 1,07 \\
\hline MAR & 1,05 & 1,12 & 1,33 & 1,16 \\
\hline ABR & 1,01 & 0,9 & 1,05 & 0,99 \\
\hline MAI & 1,13 & 0,92 & 0,88 & 0,98 \\
\hline JUN & 1,21 & 1,21 & 0,5 & 0,85 \\
\hline JUL & 1,08 & 0,68 & 0,67 & 0,81 \\
\hline AGO & 1,15 & 1,05 & 0,96 & 1,05 \\
\hline SET & 1,57 & 1,16 & 0,95 & 1,23 \\
\hline OUT & 1,57 & 0,8 & 1,02 & 1,13 \\
\hline NOV & 1,66 & 0,6 & 0,35 & 0,82 \\
\hline DEZ & 1,26 & 1,12 & 0,23 & 0,87 \\
\hline
\end{tabular}

Fonte: Autores.

\section{(cc) EY-NC-SA}


Figura 12 - Evolução em 2017 do IP3 - Perspectiva Processos Internos do BSC

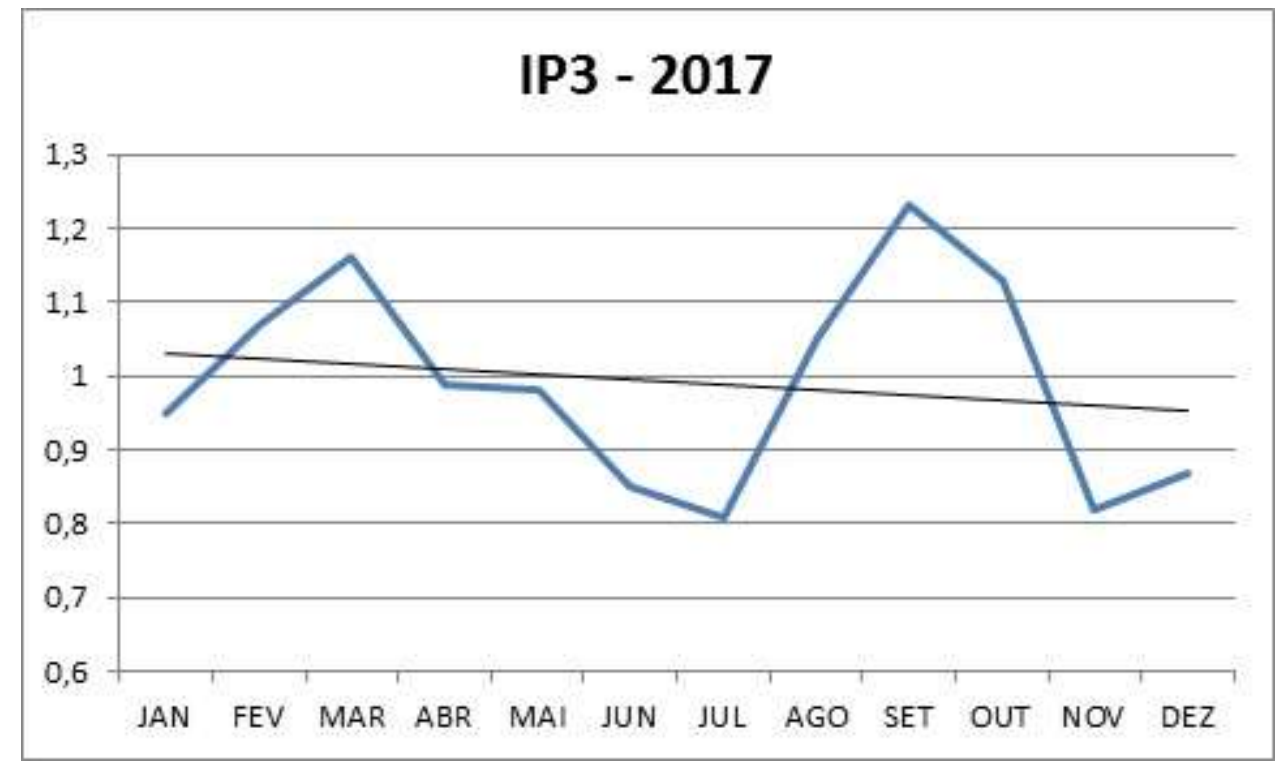

Fonte: Autores.

Tabela 4 - Entrada e Saída IC, de N4

\begin{tabular}{|l|r|r|r|r|r|}
\hline \multirow{2}{*}{ MÊS } & \multicolumn{5}{|c|}{ ENTRADAS } \\
\cline { 2 - 6 } & IP1 & \multicolumn{1}{|c|}{ IP2 } & \multicolumn{1}{|c|}{ IP3 } \\
\hline JAN & 0,85 & 1,18 & 0,95 & 0,58 & 0,84 \\
\hline FEV & 0,84 & 0,95 & 1,07 & 0,57 & 0,81 \\
\hline MAR & 0,98 & 1,12 & 1,16 & 0,51 & 0,86 \\
\hline ABR & 0,96 & 1,07 & 0,99 & 0,63 & 0,91 \\
\hline MAI & 1 & 1,14 & 0,98 & 0,73 & 0,96 \\
\hline JUN & 0,96 & 1,04 & 0,85 & 0,56 & 0,8 \\
\hline JUL & 0,87 & 1,15 & 0,81 & 0,5 & 0,77 \\
\hline AGO & 1,07 & 1,33 & 1,05 & 0,59 & 0,95 \\
\hline SET & 1,03 & 1,15 & 1,23 & 0,64 & 1,01 \\
\hline OUT & 1,1 & 1,31 & 1,13 & 0,7 & 1,06 \\
\hline NOV & 1,11 & 1,44 & 0,82 & 0,64 & 1 \\
\hline DEZ & 1,01 & 0,78 & 0,87 & 0,89 & 0,89 \\
\hline
\end{tabular}

Fonte: Autores. 
Figura 13 - Evolução em 2017 do IP4 - Perspectiva Aprendizado e Crescimento do BSC

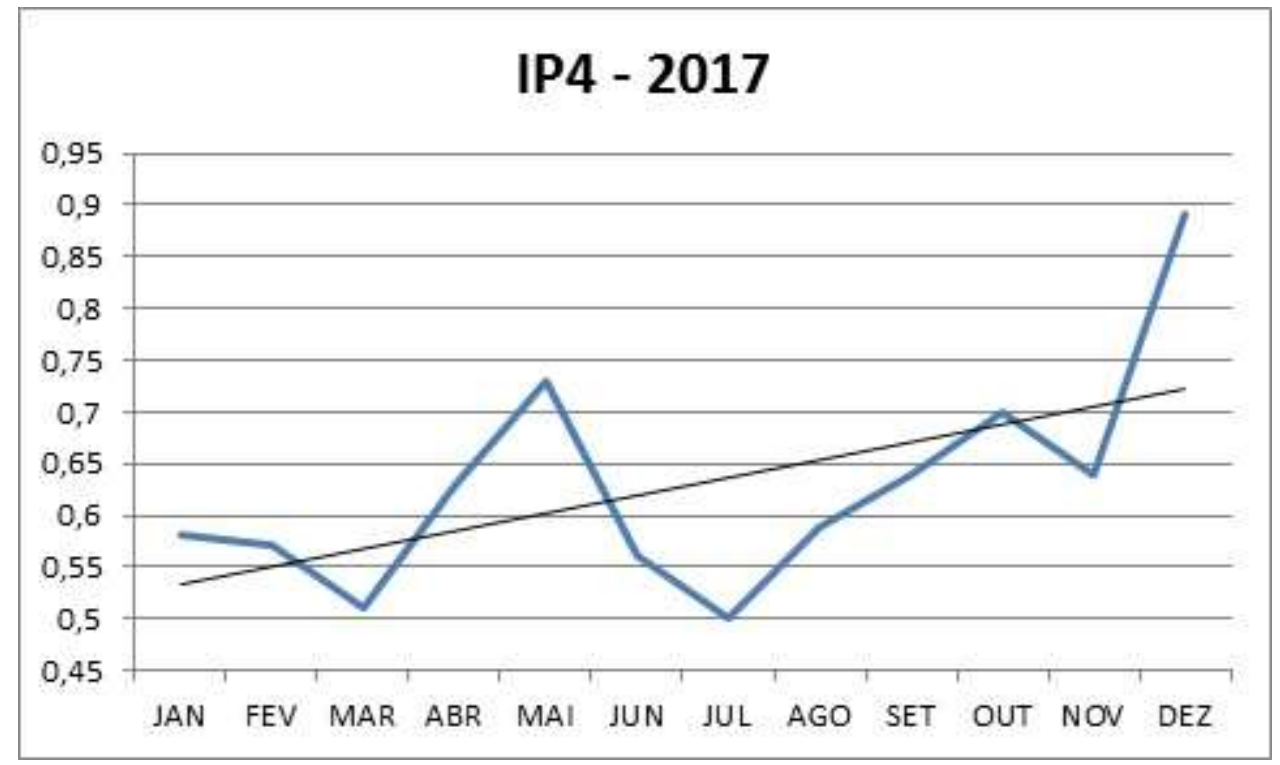

Fonte: Autores.

Figura 14 - Evolução em 2017 do IC - Indicador da Corporação - Visão Holística

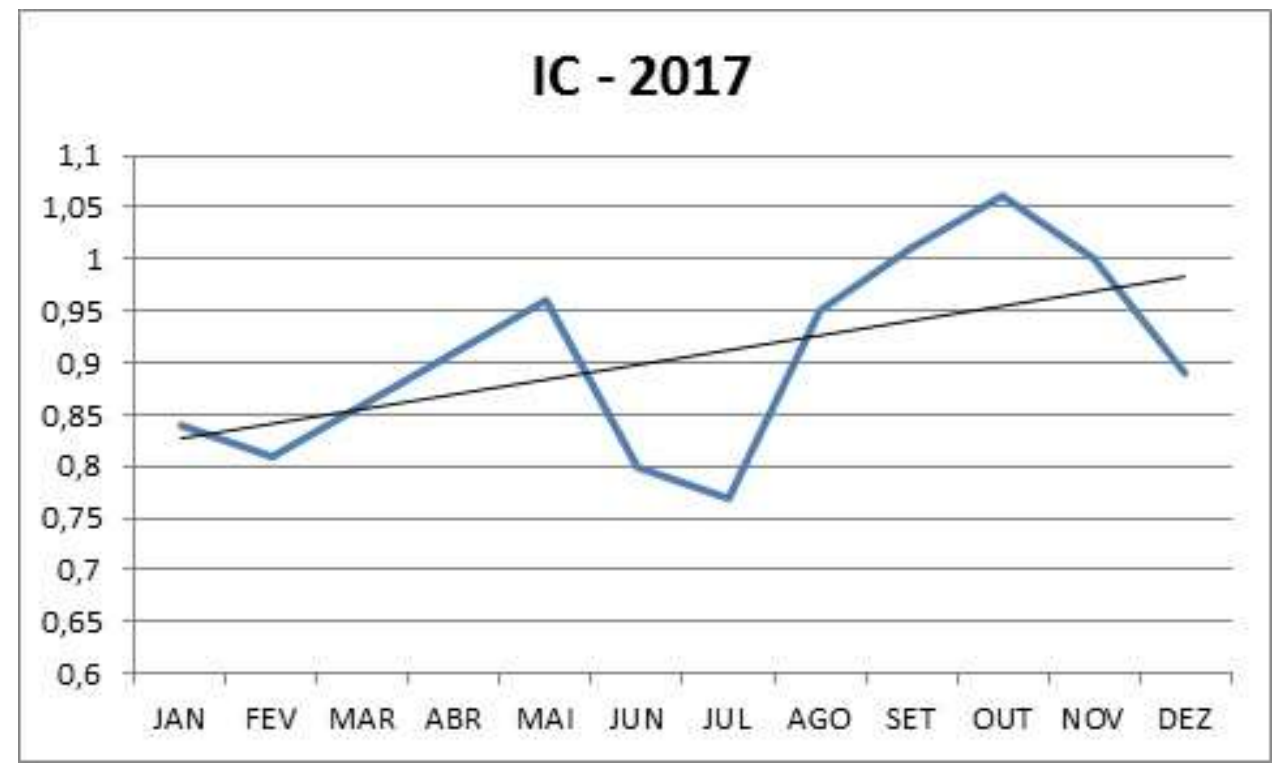

Fonte: Autores.

\section{Análises dos resultados e conclusões}

O uso do BSC pela instituição de educação como ferramenta estratégica não é objeto de análise desse estudo. Apesar disso, cabe ressaltar que o BSC é uma metodologia genérica, que é aplicável em qualquer tipo de corporação, se tornando específica quando admite usar medidas do modelo de gestão da empresa. 
Nesse contexto vale lembrar que uma das deficiências encontradas na implantação do BSC na instituição de ensino é a impossibilidade de visualização da contribuição de todas as medidas usadas pela empresa, refletindo a visão corporativa sistêmica.

Considerando-se então que a geração dos dados de entrada para o modelo matemático foi por intermédio dos dados do BSC da empresa de ensino, entende-se que o modelo matemático é específico, isto é, não é passível de utilização em outra empresa.

Apesar disso, denotou-se que o uso de RNA com a Teoria Fuzzy pôde agregar de valor considerável para a gestão da empresa do estudo de caso, pois com o modelo matemático é possível acompanhar o desempenho sistêmico da corporação utilizando-se série histórica.

Cabe também ressaltar que o modelo matemático apresentou respostas adequadas às necessidades da corporação e está em aderência ao que foi proposto nos objetivos desse trabalho, pois permitiu gerar indicadores parciais e um geral para análise holística da corporação.

Quanto aos resultados gerados pelo modelo matemático se destaca inicialmente a tendência de queda de IP3 em 2017, destoando dos outros três indicadores parciais. Este é um indicativo de prioridade de ação no tocante ao sistema gerencial que trata da gestão de processos, pois se entende que a reversão de tal tendência interferirá, diretamente, no IC, melhorando-o substancialmente.

Apesar de apresentar tendência de melhoria, O IP2 indica suave crescimento. A atuação do planejamento tático, que vincula as ações nacionais estratégicas com o desenvolvimento operacional, poderá atender melhor as necessidades dos seus clientes, aperfeiçoando tal indicador.

No tocante ao IC, observam-se vales que ocorrem nos meses de fevereiro, junho, julho e dezembro, em sintonia com IP1, que está associado aos aspectos financeiros da instituição. Há indicativo que devido às bruscas variações de receita ocorrem interferências diretas no produto oferecido ao mercado: ensino e profissionalização de pessoas.

Descendo ao nível das métricas, ou seja, das variáveis de entrada, foi possível também constatar que para melhor ajuste linear, mitigando-se, principalmente, os vales, será preciso tomar medidas gerenciais nas seguintes variáveis VEF3, VEF5, VEF6, VEF8, VEF9 e VEF10.

Para o crescimento da VEF3 será preciso que ocorra redução de custos operacionais e administrativos, parcerias e negociações de contratos com fornecedores e melhor utilização dos ativos para que se obtenha eficiência na aplicabilidade dos investimentos, de acordo com os cursos que estão sendo oferecidos pela instituição.

Para VEF5 e VEF6 é fundamental que haja um suporte às operações, por meio do aumento da qualidade de processos ao menor custo possível, alcançando assim a satisfação total do cliente.

Já para VEF8 e VEF9 nota-se que é essencial a padronização e a qualidade dos processos internos, visando garantir a centralização e otimização dos procedimentos operacionais, fazendo com que seja possível maior agilidade na parte interna da empresa. 
E, por último, a VEF10 denota a necessidade de investimento em treinamento e capacitação para os empregados, de modo que eles consigam produzir com maior qualidade e de forma mais aprimorada, realizando-se também análises para redução de desperdícios de tempo e atividades, redundando em maior motivação e engajamento dos colaboradores.

Por intermédio do estudo de caso verificou-se a influência dos indicadores parciais e de IC, que refletem os pilares do BSC e a visão holística da instituição, respectivamente.

As influências das métricas nos indicadores parciais e, deles, no Indicador da Corporação, puderam ser consideradas pelo uso das RNA, que permitem processamento de dados paralelos, com universos de discursos diferentes. Além disso, o processamento neuronal pelo uso da Teoria Fuzzy, possibilitou a vinculação das variáveis de entrada e uma única variável de saída, fazendo o papel de multiplexador de sinais.

\section{Referências}

Adamowicz, E. C., Barboza, A. O., \& Sampaio, M. E. de C. e S. (2002, outubro). Redes Neurais e Redes NeuroFuzzy aplicadas à análise econômico-financeira de empresas. Anais do XXII Encontro Nacional de Engenharia de Produção, Curitiba, PR, Brasil.

Amendola, M., Souza, A. L. de., \& Barros, L. C. Manual do uso da teoria dos conjuntos Fuzzy no MATLAB 6.5. Disponível em:<https://www.ime.unicamp.br/ laeciocb/manual_fuzzy_matlab.pdf>.

Batocchio, A.; Minatogawa, V.L.F.; Anholon, (2016) R. Proposal for a Method for Business Model Performance Assessment: Toward an Experimentation Tool for Business Model Innovation. Disponível em < https://scielo.conicyt.cl/pdf/jotmi/v12n1/art07.pdf>. Acesso em 28 de jan. 2018

Costa I.S.G.; Costa, J.A.C. e Nobrega K.C. (2018). Desenvolvimento de modelo de balanced scorecard para instituições privadas de ensino fundamental e médio. In: Revista Produção Online, 18(4), 1181-1205.

Coutinho, A. R., \& Kallás, D. (Org.). (2005). Gestão da Estratégia: Experiências e Lições de empresas brasileiras. Rio de Janeiro: Campus.

Gadelha M.A.; Mâsih R.T. (2007) Alinhamento estratégico em incubadoras de empresas: Proposta de um sistema de gestão baseado no Balanced Scorecard. Disponível em <http://www.abepro.org.br/biblioteca/ENEGEP2007_TR630468_0245.pdf>. Acesso em 31 de jan. 2018.

Ghelman, S. (2006) Adaptando o Balanced Scorecard aos preceitos da nova gestão pública. Disponível em <http://repositorios.inmetro.gov.br/handle/10926/647>. Acesso em 30 de jan. 2018

Gil, A. C. (2008). Métodos e técnicas de pesquisa social (6a ed.). São Paulo: Atlas.

Kaplan, R. S., \& Norton, D. P. (1997). A estratégia em ação: BSC. Rio de Janeiro: Campus.

Knoll, A.C. (2018) Gestão estratégica de tecnologia da informação com uso de BSC: uma pesquisa-ação em uma instituição pública federal brasileira Dissertação de mestrado, Universidade Federal de São Carlos. 
Lima, J.E.D.R. (2009) Construção e implementação do Balanced Scorecard em uma organização educacional: O caso do Serviço Nacional de Aprendizagem Comercial do Rio Grande do Norte - SENAC RN. Disponível em < https://repositorio.ufrn.br/jspui/handle/123456789/14970>. Acesso em: 15 ago. 2017

Lutif Junior, Jorge Assef. (2012) Gestão de organização sem fins lucrativos: Uma avaliação de desempenho através do Balanced Scorecard. Disponível em < http://repositorio.ufrn.br:8080/jspui/handle/123456789/15038 >. Acesso em: 15 ago. 2017

Mario, F.A. e Verdu, F.C. (2015) Adoção da perspectiva de empregados no BSC: Análise e proposta de melhoria do controle estratégico em uma rede hoteleira. Disponível em <https://www.researchgate.net/publication/315701579_Adocao_da_perspectiva_de_empregados_no_BS C_Analise_e_proposta_de_melhoria_do_controle_estrategico_em_uma_rede_hoteleira>. Acesso em: 30 jan. 2018

Mâsih, R.T.; Marinho, S.V.; Selig, P.M. (2002) A utilização do Balanced Scorecard em empresas sem fins lucrativos: Um estudo de caso. Disponível em <http://www.academia.edu/download/30227637/enegep2001_tr72_0363.pdf>. Acesso em: 15 set. 2017.

Medel-González, F.; García-Ávila, L.F.; Salomon, V.A.P.; Marx-Gómez, J.; Hernández, C.T. (2016) Sustainability Performance Measurement with Analytic Network Process and Balanced Scorecard: Cuban Practical Case. Disponível em <http://www.scielo.br/pdf/prod/v26n3/0103-6513-prod-01036513189315.pdf>. Acesso em 05 de fev. 2018.

Medeiros, A.V. de., Souza, F. E. C., \& Maitelli, A. L. (2003). Implementação de Um Sistema de Extração de Conhecimento de Redes Neurofuzzy, Universidade Federal do Rio Grande do Norte, II Workshop Técnico Científico do DIMAp.

Oliveira, D. de P. R. de. (2007). Planejamento estratégico: conceitos, metodologia, práticas (23a ed.). São Paulo: Atlas.

Pereira, F.E. (2014) O Balanced Scorecard na gestão de organizações sem fins lucrativos: O estudo de caso no SENAC/SC. Disponível em <https://repositorio.ufsc.br/handle/123456789/87530>. Acesso em: 15 ago. 2017.

Petri, C.A.; Amante, C.J.; Duarte, J.F.; Cunha, P. e De Mello, L.H.W. (2019) A elaboração do planejamento estratégico do IFSC 2015/2019 e o plano anual de trabalho In: Brazilian Journal of Development, v. 5, n. 1, p. 639-654.

Rezende, S. O. (2005). Sistemas Inteligentes: fundamentos e aplicações. Barueri: Manole.

Rodrigues, L.H.; Pantaleão, L.H. e Schuch, C. (2003) Uma abordagem para construção de sistemas de indicadores alinhando a Teoria das Restrições e o Balanced Scorecard. Disponível em $<$ http://gmap.unisinos.br/recursos-didaticos/trensurb/mod1-gestao-publica/artigoenanpad\%20Indicadores.pdf>. Acesso em: 31 jan. 2018

Ross, Timothy J. (2010) Fuzzy logic with engineering applications 3rd ed.ISBN 978-0-470-74376-8, John Wiley \& Sons.

Shaw, I. S., \& Simões, M. G. (1999). Controle e Modelagem Fuzzy. São Paulo: Edgard Blücher.

Souza, F.S. (2005) Implementação do Balanced Scorecard (BSC) em uma organização do Sistema S [manuscrito]: O caso SENAI/BA. Disponível em < http://tede.unifacs.br/tede/handle/tede/140>. Acesso em: 15 ago. 2017 
Silva, E. L., \& Menezes, E. M. (2005). Metodologia da Pesquisa e Elaboração de Dissertação (4ạ ed.). Universidade Federal de Santa Catarina, Florianópolis, SC, Brasil.

Sucena, M.P. (2007). Modelo Fuzzy para Subsidiar a Alocação de Recursos Financeiros em Sistemas de Transportes sobre Trilhos Tese de Doutorado, Universidade Federal do Rio de Janeiro, COPPE.

Tanaka, K. (1997). An Introduction to Fuzzy Logic for Practical Applications. Nova York: Springer.

Vellasco, M. M. B. R. (2009). Redes Neurais Artificiais. PUC-Rio, Departamento de Engenharia Elétrica, Rio de Janeiro, RJ, Brasil.

Wang, DX. (1996). A course in Fuzzy Systems and control. (1a ed.). New Jersey: Prentice-Hall.

Recebido em: 21 jun. 2018 / Aprovado em: 25 jun. 2019

Para referenciar este texto

American Psychological Association (APA)

Sucena, M. P., \& Haya, T. B. (2020). Redes neuro-fuzzy subsidiando o balanced scorecard em processo decisório holístico: o caso de uma instituição de educação profissional. Exacta, 18(3), 517-539. https://doi.org/10.5585/ExactaEP.v18n3.8823. 